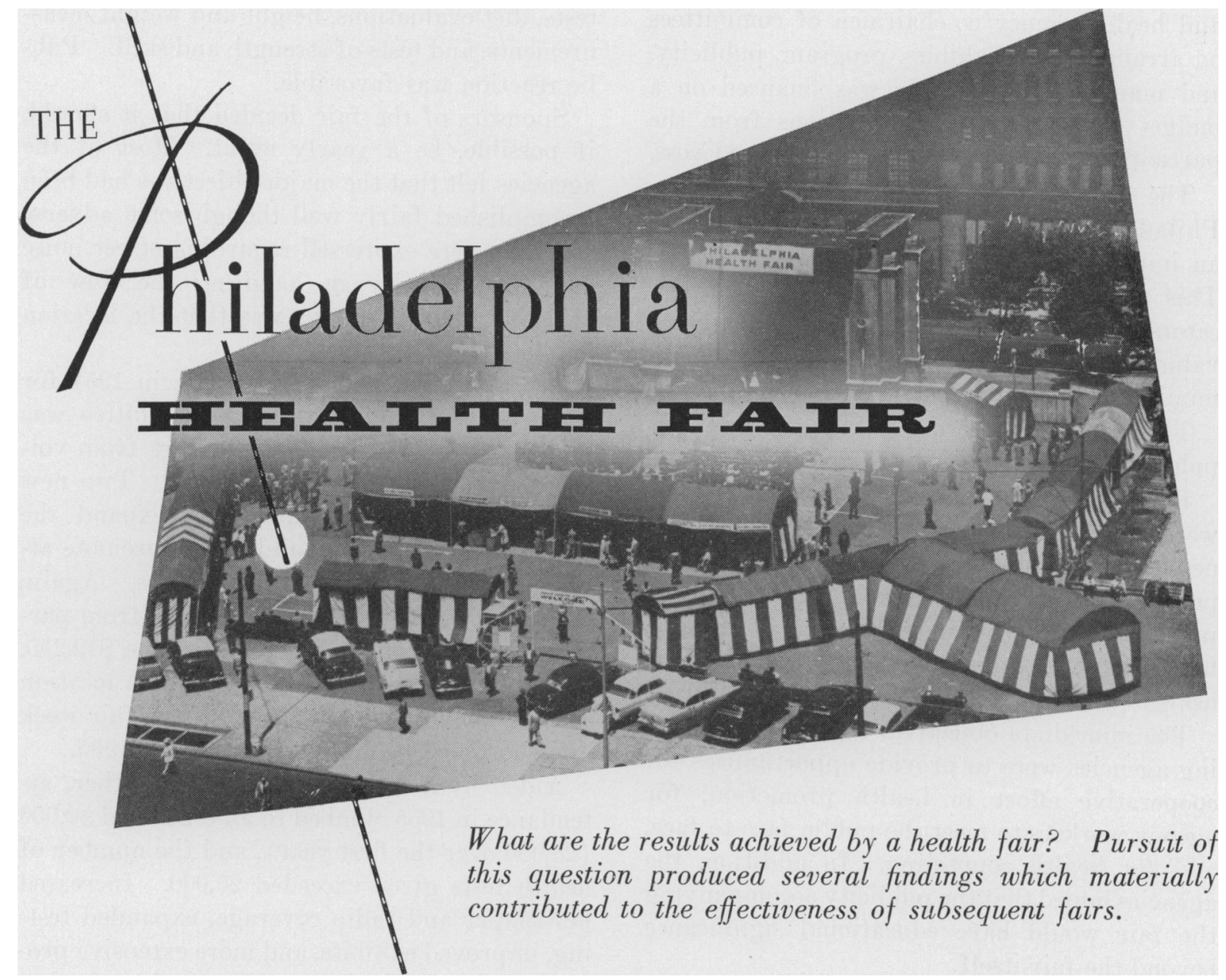

BY JAMES P. DIXON, M.D., IRWIN M. ROSENSTOCK, Ph.D., JOHN B. DIBELER, M.P.H., and WILLIAM A. ALLEN, M.P.H.

$\mathrm{P}$ HILADELPHIA's three health fairs, the first in 1954 and the latest in 1956, were the setting for an illuminating experience in the evaluation of health education techniques. This story about the effectiveness of the health fair in bringing community agencies together provides a valuable footnote to this experience.

Dr. Dixon is commissioner, Philadelphia Department of Public Health. Mr. Allen is director of the department's office of education, and Mr. Dibeler is director of education, Philadelphia division of the American Cancer Society. Dr. Rosenstock is assistant chief of the Behavioral Studies Section, Division of General Health Services, Public Health Service.
The Philadelphia Junior Chamber of Commerce invited official and voluntary agencies and professional societies to help plan the first health fair in Philadelphia and the first health fair in any large city. That was in 1952.

Early in 1954, when leadership and financing seemed certain, the Jaycees organized a steering committee, formed the nucleus of an executive committee, and appointed a treasurer and legal consultant.

The city department of public health, the health and welfare council, the board of public education, and county medical, dental, and nursing societies were among the agencies represented on the steering committee. The de- 
cisions of this group were carried out by Jaycee and health agency co-chairmen of committees on arrangements, exhibits, program, publicity, and manpower. The fair was financed on a budget of $\$ 10,300$ by contributions from the participating agencies and the local Blue Cross.

The Health Education Committee of the Philadelphia Health and Welfare Council was an important catalyst in the initial planning. This committee, which included health educators from a number of local agencies, provided valuable aid in developing the fair as a communitywide activity in health education.

The fair had three major objectives for the public and three for the participating agencies.

For the public, the long-range objectives were $(a)$ to create increased health consciousness through understanding of community and personal health problems, $(b)$ to stimulate the practice of preventive medicine and periodic health examinations, and (c) to urge use of health services and other community facilities.

The immediate objectives for the participating agencies were to provide opportunities for cooperative effort in health promotion, for agency workers to meet the public face to face, and for health counseling. In addition, the agencies hoped that the publicity accompanying the fair would have educational significance beyond the fair itself.

Health fairs and health weeks, promoted by junior chambers of commerce and local health councils, are attracting enthusiastic interest throughout the country. Although this trend in health education is gaining momentum, little effort has been made to evaluate its effect on the public and the participating agencies. The Philadelphia experience illustrates the need for critical evaluation.

\section{History of the Fairs}

The first fair was held May 15-22, 1954, from 11 a. m. to 9 p. m. daily, in Reyburn Plaza, an open court opposite City Hall in the heart of Philadelphia. Health tests and exhibits presented by 40 agencies were housed in gay canvas booths. A large tent served as a film theater.

Despite one day of unfavorable weather, 52,000 persons attended the fair, and more than
7,000 received chest $\mathrm{X}$-rays, blood and hearing tests, diet evaluations, height and weight measurements, and tests of strength and skill. Public reaction was favorable.

Sponsors of the fair decided that it should, if possible, be a yearly event. Most of the agencies felt that the major objectives had been accomplished fairly well though some adverse opinions were expressed regarding street noise and the difficulty in handling the flow of visitors. The consensus was that the location had been satisfactory.

Tentative plans were made late in 1954 for a second fair. The executive committee was broadened to include more members from voluntary and official health agencies. Two new committees were added, one to expand the health testing program and one to promote attendance through community groups. Again, financing was through contributions from participating agencies. The budget was $\$ 12,250$. This fair was scheduled for the same location at the same hours as in 1954, but the fair week was shortened to 6 days, May 16-21, 1955.

Aided by a week of favorable weather, attendance in 1955 climbed to an estimated 80,000 (28,000 over the first year), and the number of health tests given exceeded 20,000. Increased newspaper and radio coverage, expanded testing, improved exhibits, and more extensive programing helped increase attendance also. Forty-one agencies presented exhibits, demonstrations, health tests, films, and programs.

\section{Organization and Operation}

The health fair required days and hours of spade work by the groups and agencies that conceived the idea and by the committees and numerous subcommittees. In addition to determining policy regarding arrangements for exhibits, publicity, and financing, the steering committee developed the objectives, opened communication lines, and advised on problems. in professional relationships. Presentation of the fair was the responsibility of the executive committee. To coordinate planning for the forty-odd agencies and to handle the details. of booth construction and rental, the executive. committee hired a fair manager 3 months before the fair. The manager's booth was located' 
near the main entrance, where it served as the center of administrative operations.

The publicity committee employed a local public relations agency to issue news releases to metropolitan and neighborhood newspapers, to write television and radio announcements, and to publicize news events related to the fair. News releases began several weeks before the fair, built to a high pitch at the opening, continued throughout the week of the event, and ended in a final roundup of pictures and stories.

The stage of the bandshell served as the focal point for the various programs, designed to draw attendance and entertain as well as to educate. A master of ceremonies announced programs, called attention to future demonstrations, and told the audience about the objectives of the fair and its sponsors. A nurseof-the-year award, band concerts, pageants, and talks by the health commissioner, the presidents of the medical and dental societies, and other health authorities were included in the staged program.

Shortly after the fair, the agencies and committees evaluated the effectiveness of their own contributions and exchanged this information for use in planning the next year's fair.

Although planning of the second health fair represented an improvement over the initial efforts, committee members agreed that further improvement was desirable. Three weeks before the opening the executive committee requested assistance from the Public Health Service in planning an objective evaluation of the educational effectiveness of the fair. Committee members felt that the request should be made even though the time for planning was short. 'The Public Health Service agreed to help.

The community objectives for the 1955 fair were the same as those for the first fair. Obviously, any attempt to measure success in achieving these in a metropolitan area would face formidable obstacles.

\section{Evaluation Process}

In view of those obstacles, an attempt was made to evaluate progress by a method described in detail elsewhere (1). In brief, it measures success with intermediate objectives that are importantly related to long-range objectives.

The short time available for planning imposed certain limitations on the evaluation. No evaluation of the long-range objectives was attempted even though certain of these might have been closer to realization than certain intermediate objectives; neither was there an attempt to measure the success of the fair in improving working relationships among the local health agencies, a result that seemed implicit in the production of the fair.

Accordingly, the executive committee agreed that evaluation would be confined to the following intermediate objectives:

1. For long-range objective $b$, noted above, the intermediate objective was to foster participation in the health tests planned for the fair.

2. For long-range objective $c$, the intermediate objective was to increase knowledge of community health services.

To evaluate success with these objectives, we interviewed persons entering and leaving the fair. Those interviewed on entering were not interviewed on leaving. Differences in knowledge between the two groups could be attributed to experience with the health fair. Through open-end questions, respondents would have an opportunity to discuss their impressions of the fair. In all, 215 adults were questioned on entrance and 202 on departure. The interviews, conducted by volunteers, students from Temple University, lasted 5 to 15 minutes.

The following summary lists the main points in the evaluation :

1. Nearly half (48 percent) of the fair visitors took at least 1 health test, and a fourth took 2 or more. No person took more than 4 tests.

2. In general, more men, more younger people, and more highly educated people visited the fair than would be expected on a purely random basis. Less well-educated people, older people, and, to some extent, women did not attend the fair in proportion to their numbers in the local population.

3. Evaluation of the fair objectives makes it clear that the long-range objectives were 
such that the limited educational activity of the health fair could not reasonably be expected to achieve them by itself.

4. Within the limitations of the design of the inquiry, it could not be shown conclusively that the fair succeeded in increasing knowledge about local health services.

The intermediate objectives, as stated, were not met in full. In view of this, the participating agencies recognized the need for more realistic objectives. Agency discussion of the evaluation resulted in a review of individual and group philosophies of health education, a greater appreciation of the need for evaluating other efforts at health education, and immediate plans to exploit more effectively the education potential of the fairs. Self-evaluation by the participating agencies indicated that most felt they had progressed toward goals. Some reported that use of their services increased following the fair.

\section{Implications for the Future}

The findings of the evaluation have many implications. In this context, it is less important to ask whether 48 percent participation in health tests met expectations than it is to ask how to increase participation. Similar questions may be asked about the other findings.

Are program objectives realistic and can they be achieved?

Specific objectives should be agreed upon by all participants early in the planning stage. Evaluation of a program seldom can be effective if objectives are vague. For evaluation to be effective, long-range objectives essential to initial planning must be associated with realizable short-term objectives. This process can be facilitated by including persons responsible for the evaluation early in the discussions.

\section{What audience are we trying to reach?}

Identification of the desired audience should be made early because the entire process is colored by that decision. The nature of the Philadelphia health fair, with its wide range of messages, made it difficult to identify a specific audience, although adults were more desired than youngsters. It was felt that chil- dren, welcome of course, receive health education more effectively through schools.

The location of the fair, in the heart of the city, and the means used to promote it explain in part the presence of relatively large numbers of young people, men, and visitors of relatively extended schooling. The fair, with its gaiety and hubbub, naturally attracted many visitors who were in the neighborhood. When asked how they happened to come to the fair, the men, the young people, and those with extended schooling responded much more frequently than others that they were motivated by seeing the fair itself. This supports the idea that the sight and sound of the fair will bring more visitors than advertisement in the newspapers. The less extensively schooled, the older adults, and, to a lesser degree, women, tended to stress newspapers and public advertising as their reason for attending the fair. This occurred despite the fact that these groups probably had less exposure to these forms of public communication than the others. Had the fair been held in another part of the city, quite different groups might have attended.

Findings on the nature of the audience should not be attributed to the single factor of location. In tuberculosis case-finding programs, participation is poorest in precisely the same population groups whose attendance was poorest at the health fair. Hochbaum (2) suggests that differences in motivation also may help to account for the nature of the audiences.

Do the exhibits permit rapid inspection and learning?

The 1955 health fair included exhibits, health tests, films, and health programs. Although to view all the exhibits, films, and programs and participate in all tests would undoubtedly have required several hours, the median amount of time spent at the fair was only 45 minutes, or only 1 minute for each of the presentations offered. There is no reason to believe, however, that an individual could not have had a satisfactory learning experience if he had spent the 45 minutes in taking 2 or 3 health tests, viewing a film, and seeing several exhibits.

Exhibits that were top heavy with copy received little attention, but displays consisting of only a few lines of carefully edited copy and 
illustrated with large, clear photographs often attracted study. Demonstrations and other eye-catchers increased attendance at exhibits.

Are the exhibits and health tests staffed by attendants qualified to provide desired information or make needed referrals?

Attendants at exhibits should be well informed about the functions of their own agency, the purposes of the exhibit they represent, and the objectives of the health fair. They should be able also to refer inquiries to other sources of information. Orientation can be accomplished by the agency itself and by a general briefing for all attendants.

Incomplete information on the part of persons administering the health tests may have contributed to the failure of some fair visitors to identify health tests when they were questioned on leaving the fair. One test in particular was interpreted inadequately and resulted in undue concern over failure to attain an average score.

Those giving health tests should receive short, intensive training to familiarize themselves with the purposes of the test, its limitations, and the exact interpretation of the results. Explanatory pamphlets and posters will support the explanations by the attendant.

Misconceptions result from failure to explain the health tests. For example, some individuals confuse a test for diabetes with a test for venereal disease. Listing all tests on the program and posting the list in a conspicuous place will tend to relieve such confusion.

\section{Are presentations readily accessible?}

Exhibits, health tests, and other presentations should be accessible to everyone. Lanes between rows of booths should provide for an unobstructed flow of traffic. If it is necessary to keep lines of people waiting to take tests and view exhibits, the lines should be arranged to avoid blocking other displays. Announcements over a public address system aid in directing visitors to uncrowded exhibits and tests.

Have the programs had careful planning?

In general, the main objective of health fair programs is to motivate good health practices.
One method of developing a program is to plan with agencies contributing to the chosen theme. Each minute in a program should be planned to contribute to the objectives.

\section{The Learning Process}

Health education studies have shown that what people learn reflects their immediate personal interests and concern. Simply stated, a hungry man notices a restaurant that a satiated person might overlook. In general, without motivation, learning does not proceed. Other studies have shown that the pattern or organization of motives in people is quite individual and perhaps unique.

What implications do these facts have for a health fair?

In any group of people assembled at a fair, some will not be motivated by the subject or theme. Others may be strongly motivated in areas served by some of the material but not as much in others. Since patterns of motives, as well as learning capacities, are individual, each person would be expected to learn at his own pace and in his own direction.

On the basis of these principles, it could be predicted that the amount of information gleaned from the wealth of material at a health fair would vary from person to person. Also, no individual would learn exactly what is learned by any other. A health fair cannot be equally successful for all participants, nor is it at all successful for some.

One might maintain that moderate success might still be achieved with individuals who have a personal concern with health. This would be true if enough people had such concern and if the material presented were appropriate. Preliminary explorations, however, suggest that relatively few people have concerns that they identify with the need to improve health practices. Of course, the health worker knows that a person's health status strongly influences his ability to function and obtain what he wants, but most people either do not know this or behave as if they do not know, with gross indifference to their health.

These problems pose a difficult question for health educators. How can we help people improve health practices when they do not believe they have health needs? 
In general, it appears necessary to plan health programs in such a way that the unique needs or motives of each individual can be served insofar as possible. Efforts should be made to tie in with whatever personal needs the individual believes he has. Program development must be based on valid information about the concerns of persons whose cooperation is sought. Health consultation by a wellinformed staff at the fair booths offers the possibility of uncovering some of these needs, and, at least partially, of meeting them.

\section{Theory Info Practice}

Theories developed from the 1955 evaluation became practice in 1956, when the third annual health fair was held October 12-13 and 15-18 in Reyburn Plaza. The evaluation had provided definite guidelines for presenting exhibits and tests. As a result visitors were given a better opportunity to learn about personal and community health, and the services of health and welfare agencies.

More realistic short-term objectives were developed along with suggestions to participants for achieving them.

Store window posters and mass distribution of fliers were not used to promote the fair because the evaluation had shown them to be of limited value in attracting an audience.

A subcommittee on volunteer training was organized to assure that attendants at the booths were better informed about the health tests, the exhibits, the fair in general, and their own agency in particular.

On the recommendation of the volunteer training committee, each agency provided descriptive material on its services for the use of persons staffing the booths and a list of community resources to assist them in making referrals.

The cancer society, the department of public health, and many of the other agencies met with the staff members and volunteers who were to man their health tests and exhibits.

These meetings provided facts about the fair sponsors: background, history, functions, and purposes; why the particular agency was taking part; its relationship to other agencies; and the value of health consultation.
Organizations presenting health tests explained to their staff members the purposes and limitations of the tests, how those examined would learn of the results, and where tests are available regularly.

Because the evaluation had pointed up the need, special efforts were made to improve interpretation to those examined of results of the tests.

Mimeographed sheets, listing the purpose of the particular test, what constitutes a normal result, and the mechanics of followup, were distributed at the fair.

$\Lambda$ sign posted near the clinitron, the device for testing sugar content of blood, explained that a blue color in the test sample meant a normal condition and that a colorless sample indicated possible diabetes. In this way, people viewing the operation of the clinitron could watch the progress and final result of a test. The use of leaflets and signs in front of booths reduced anxiety about test results and gratified curiosity.

Spot checks at the 1956 fair revealed that persons staffing the booths were better informed about exhibits, tests, and agency and health fair purposes than in the preceding year.

\section{Summary and Conclusions}

To summarize the Philadelphia experience with three health fairs, we would say that in planning a health fair or any other health education activity it is necessary to set realizable short-term objectives as well as long-range objectives. The attainment of these will provide encouragement to participating groups. Persons responsible for evaluation should be included as early as possible in program planning. By making evaluation results available to all concerned-in Philadelphia these were the sponsoring and participating agencies-programs in the future can be improved.

The location of the fair greatly determines who will attend. Fairs should use proved techniques for attracting an audience and motivating it to positive steps. Careful instruction is essential for those who are to give the health tests and explain exhibits to visitors.

A health fair may be viewed as a project which is linked with other community health 
activities. Additional critical evaluation may give information about the value of health fairs to a community, their priority in health education, and their opportunities for providing individual consultation. Although their value in building relationships and improving cooperation among community agencies seems evident, their educational values for the public are not certain.

Through further research, it may be possible to determine the educational potential of the health fair and discover effective ways of realizing such potential.

\section{REFERENCES}

(1) Knutson, A. L.: Eraluating program progress. Pub. Health Rep. $70: 30.5-310$, March 195\%.

(2) Hochbaum, G. M.: Why people seek diagnostic X-rays. Pub. Health Rep. 71:377-380, April 1956.

\section{technical publications}

\section{Research and Training \\ Grants and Awards of the Public Health Service}

\section{Information Statement}

PHS Publication No. 415. Revised, October 1956. 29 pages.

Included in this revised brochure are several new programs initiated subsequent to July 1956, such as health research facilities, senior research fellowships, and mental health career teacher grants. It has, in addition, information on research grants, field investigation grants, career investigation grants, research fellowships, traineeships, and training grants.

The booklet describes liberalized policy governing the budgeting of funds and the use of unexpended funds in approved grants, and reflects the increase in stipends under the traineeship and research fellowship programs.

\section{The Public Health Service in Occupational Health}

PHS Publication No. 490. 1956. 16 pages; illustrated. 20 cents.

This booklet describes the work of the Public Health Service in its 40 years of research in occupational health hazards. Photographs depict various phases of program operation, and the narrative material is intended for a general rather than a specialized audience.

The publication points out that, while great strides have been made in eliminating occupational disease in the past century, new hazards are posed by materials and processes being constantly introduced by a dynamic technology.

Occupational Health Program activities now encompass research and field studies, promotion of preventive health services in industry, and training and consultation services, all directed toward achievement of greater health protection for the production force of the Nation.

\section{Citizen Participation in Public Welfare Programs}

\section{Supplementary Services by Volunteers}

Social Security Administration. By Evalyn G. Weller and Elizabeth $B$. Kilborne. 1956. 46 pages. 20 cents.

Addressed to the staffs of State and local welfare agencies, this booklet aims to encourage agency personnel to provide more opportunities for citizen participation in community service.
The publication discusses supplementary services and offers suggestions for developing volunteer services and for the orientation, training, and supervision of citizen volunteers.

other social agencies interested in initiating or extending volunteer services will also find the discussion helpful.

\section{National Library of Medicine}

PHS Publication No. 50\%. 11 pages.

Services of the National Library of Medicine, formerly the Armed Forces Medical Library, are listed in this folder. Included are library hours ; loan procedures ; and photoduplication, reference, translation, history of medicine, art section, and publication services.

This section carries announcements of all new Public Health Service publications and of selected new publications on health topics prepared by other Federal Government agencies.

Publications for which prices are quoted are for sale by the Superintendent of Documents, U. S. Government Printing Office, Washington 25, D. C. Orders should be accompanied by cash, check, or money order and should fully identify the publication. Public Health Service publications which do not carry price quotations, as well as single sample copies of those for which prices are shown, can be obtained without charge from the Public Inquiries Branch, Public Health Service, Washington 25, D. C.

The Public Health Service does not supply publications issued by other agencies. 